\title{
Age and Gender-Related Differences in Physical Functions of the Elderly Following One-Year Regular Exercise Therapy
}

\author{
Hiroe Sugimoto', Shinichi Demura², Yoshinori Nagasawa ${ }^{3}$ \\ ${ }^{1}$ Kyoto Women's University, Kyoto, Japan \\ ${ }^{2}$ Graduate School of Natural Science\& Technology, Kanazawa University, Kanazawa, Japan \\ ${ }^{3}$ Department of Health and Sports Sciences, Kyoto Pharmaceutical University, Kyoto, Japan \\ Email: hiropon-win@maia.eonet.ne.jp
}

Received 2 February 2014; revised 5 March 2014; accepted 13 March 2014

Copyright (C) 2014 by authors and Scientific Research Publishing Inc.

This work is licensed under the Creative Commons Attribution International License (CC BY). http://creativecommons.org/licenses/by/4.0/

(c) (i) Open Access

\section{Abstract}

Reports on physical functions during maintenance period of the elderly with cardiac and other serious diseases are limited. This study aims to clarify age and gender-related differences in their physical functions. Participants included 167 elderly individuals (males, 78; mean age, 76.5 years; $S D=6.0$ years; females, 89; mean age, 75.5 years; $S D=4.5$ years) who participated in a 1-year regular exercise therapy twice a week. The following eight physical function tests were selected: grip strength, 10-m obstacle walking time, one-legged balance with eyes open, sit-ups, sitting trunk flexion, 6-min walk, stepping by sitting position, and a timed up \& go (TUG). Two-way analysis of variance was used to examine mean differences by gender and age: young elderly group (aged 65 74 years) and old elderly group (aged $\geq 75$ years). In the grip strength, sit-ups, 6-min walk, 10-m obstacle walking time, stepping by sitting position, and sitting trunk flexion tests, males were superior in the former four tests, and females were superior in the latter two tests. The young elderly group was superior in all tests except for sit-ups compared with the old elderly group. The balance during one-legged with eyes open test was superior in males compared with females in the young elderly group, but decreased in males in the old elderly group. In conclusion, physical functions of the elderly during maintenance period are different between genders. Muscle strength, muscle endurance, whole-body endurance, and walking ability are superior in males, whereas flexibility and agility are superior in females. The old elderly group was inferior in all the elements of physical function except muscle endurance.

\section{Keywords}

Elderly during Maintenance Period; Young Elderly Group; Old Elderly Group; Exercise Therapy; Physical Function 


\section{Introduction}

To extend health expectancy and ensure quality of life (QOL), it is important for the elderly to prevent lifestyle-related diseases, to establish regular exercise, and to actively maintain and improve physical fitness [1] [2]. The physical functions required for independent living in the elderly are influenced by their physical frailty [3] [4]. Elderly individuals with inferior cardiorespiratory endurance and muscle strength have a high risk of lifestyle-related diseases such as obesity, hypertension, and high blood sugar [5] [6]. Maintenance of various physical functions contributes to a reduction in the total mortality and incidence of diabetes [7]-[9]. On the other hand, a decline of physical functions in the elderly affects the population's fall rate [10] [11]. Bone fractures caused by falling greatly limit the elderly's physical activity and leads to a decrease of QOL and physical functions. Hence, adequately identifying physical functions of the elderly is important to prevent disease and predict fall incidences. However, the elderly with cardiac disease and other serious diseases during maintenance period are often excluded from studies considering their safety, and thus, physical function tests have not been sufficiently performed in them [12]. Exercise tolerance (whole-body endurance) is improved by exercise therapy [13]-[15], but it only accounts for a part of the physical functions. Physical functions include various elements such as muscle strength, flexibility, agility, and equilibrium. Therefore, it is important to comprehensively measure and evaluate many physical functions particularly for the elderly during maintenance period [13] [16].

A maintenance period is necessary to maintain good physical and mental functions throughout life, which can prevent recurrence, improve QOL, and extend life prognosis of the elderly [17]. In Japan, several policies have been implemented for the elderly, mainly in primary prevention. However, adequate studies have not been performed for the elderly during maintenance period, and its evidence related to physical functions is poor [13]. The elderly play sports and undergo exercise therapy in health promotion facilities (fitness clubs) and gymnasiums. However, because problems occur when transferring patient information from medical institutions to sports facilities, the management and manpower is limited to a few authorized incorporated non-profit organizations [13]. In exercise therapy, sports, such as table tennis and soft tennis, and aerobic exercise, such as walking or bicycle ergometer, are employed for primary and secondary prevention of lifestyle-related diseases or during the maintenance period for the elderly [17]. It is suggested that the elderly during the maintenance period as well as the general elderly population can maintain physical functions by continuing exercise therapy [13] [16]. However, characteristics of their physical functions have not been completely examined for age and gender-related differences. According to previous studies [2] [18], physical functions of the elderly decrease with age. In general, males are superior in muscle strength, power, balance, and endurance, and females are superior in flexibility. The following was hypothesized in this study for physical functions of the elderly during the maintenance period: their physical functions differ between sexes, males are superior to females in all the physical functions except flexibility, and the young-old elderly group is superior to the old-old elderly group in all the physical functions.

This study aimed to address the above hypothesis by engaging the elderly who participated in a 1-year long regular exercise therapy during maintenance period.

\section{Method}

\subsection{Subjects}

Participants in the study included 167 elderly individuals during maintenance period (males: the young old elderly group $n=29$; mean age, 70.4 years; $S D=3.3$ years, the old elderly group $n=49$; mean age, 80.2 years; $\mathrm{SD}=3.8$ years, females: the young old elderly group $\mathrm{n}=45$; mean age, 71.9 years; $\mathrm{SD}=2.2$ years, the old elderly group $n=44$; mean age, 79.1 years; $S D=3.2$ years) who participated in regular exercise therapy twice a week for a 1-year period from April 2008 to December 2012. All participants resided in K city of Japan. Their symptoms stabilized during maintenance period after a serious disease including cardiac disease, and all participants were independent elderly people that do not require nursing care. The maintenance periods in this study were relevant to the following groups of elderly individuals: elderly with cardiac disease, a malignant tumor, or cerebrovascular disease; those who had undergone abdominal vascular surgery; and those with diabetes accompanied by neuropathy. Seven months had passed since the onset of symptoms in all the elderly, who were aged $\geq 65$ years with stable disease. Participants underwent the physical function tests after the enforcement of regular 
exercise therapy twice a week for one year. The main illness of participants at onset was distributed as35 old myocardial infarction, 58 angina pectoris, 5 syndrome $\mathbf{X}$, 3 arterial flutter, $\mathbf{1 0}$ arterial fibrillation, 8 bradycardiatachycardia syndrome, 4 chronic obstructive pulmonary disease, 2 abdominal aortic aneurysm, 24 diabetes, 35 malignancy, 3 brain tumor, 15 brain infarction, 4 intracerebral hemorrhage, 60 hypertension, 17 hyperlipidemia, 5 hyperuricemia, and 13prostatic hyperplasia persons (multiple answers allowed). No participant with serious disease was contraindicated for exercises during tests. The purpose of this study, measurement contents, and safety procedures as well as the right to refuse the survey and tests by a voluntary basis, was explained to all participants. After receiving written informed consent from all participants, the following survey and tests were performed. The number of days of exercise program participation for 1 year was follows: male (the young old elderly group, $45.9 \pm 16.1$ days, the old elderly group, $43.2 \pm 17.9$ days), female (the young old elderly group, $45.2 \pm 19.5$ days, the old elderly group, $44.6 \pm 18.7$ days).

The study was approved by the Ethics Committee on Human Experimentation of Faculty of Human Science, Kanazawa University (2012-27).

\subsection{Program of Exercise Therapy}

The purposes of exercise therapy prevent recurrence, care, improve QOL, and extend healthy life expectancy for the elderly during maintenance period with serious diseases in the past. It is recommended them to be carried throughout life. The single exercise program lasting approximately 80 min was as follows: 15 -min warm-up, 6-min walking, 40-min main exercise (table tennis, soft tennis, or bicycle ergometer) with 5-min rest time and 10-min cooling down. The exercise program was controlled according to individual physical function in this study.

\subsection{Measurement Items and Procedure}

The physical characteristics measured were as follows: height, weight and body fat percent. Weight and body fat percent were measured using a body fat calculator (BC-118, TANITA Co., Ltd., Japan).

\subsection{Physical Function Measurement}

The following eight physical function tests were performed: grip strength (muscle strength), 10-m obstacle walking time (walking ability), one-legged balance with eyes open (balance ability), sit-ups (muscle endurance), sitting trunk flexion (flexibility), 6-min walking (endurance), stepping by sitting position (agility), and a timed up \& go (TUG: movement ability). Grip strength of the right and left hands was measured twice on standing participants using a Smedley's hand dynamometer (TKK5401, Takei Scientific Instruments Co., Ltd., Japan), and an average value of their maximum values was used as a representative value. Sitting trunk flexion was measured twice using a trunk flexion instrument (EKJ091, EVERNEW Co., Ltd., Japan), and the higher value was used for analysis. The stepping by sitting position test was evaluated as a variable that counted the repeated stepping number from the inside of two lines at a $30-\mathrm{cm}$ interval to the outside at the same time with both legs at chair sitting position during $20 \mathrm{~s}$ [19]. The TUG test measured the time taken to walk to a cone $3 \mathrm{~m}$ away after starting from a sitting position and returning to the original seated position [20]. The method of measurement for all physical function tests, except stepping by sitting position and TUG test, was performed based on the Implementation Guidance made by the Ministry of Education [12].

\subsection{ADL Survey}

ADL was evaluated by 12 items related to daily life [12]. The ADL items consist of 4 operating areas (movement, manipulation, equilibrium, and posture-transformation). Each item was evaluated with a 3-point scale. A range of the total ADL was 12 - 36 points.The ADL scores of the elderly during maintenance period were same level as the healthy elderly (males, 32.0 points; $\mathrm{SD}=3.4$ points; females, 29.2 points; $\mathrm{SD}=4.3$ points).

\subsection{Measurement Procedures}

The measurements and survey were conducted after sufficiently explaining the content to each participant in advance. We asked them not to participate in physical function tests if they felt that the activity was too difficult. 
We confirmed that there is no trouble even if they do not respond to protect the privacy with respect to ADL survey. After confirming that there were no particular problems with physical characteristics and blood pressure (systolic and diastolic) following the 15-min warm-up that focused on stretching exercises, the physical function tests were performed [12].

\subsection{Statistical Analysis}

Statistical analysis was performed using SPSS 11.5J for Windows (SPSS Inc., Tokyo, Japan). Each measured value was represented with respect to mean and standard deviation by gender. A two-way ANOVA with unpaired measures was used to examine significant mean differences (gender $\times$ age) for the physical function tests: young elderly group (aged 65 - 74 years) and old elderly group (aged $\geq 75$ years). When significant interaction and main effects were found, a multiple-comparison test was conducted using Tukey’s honestly significant difference method. An alpha level of 0.05 was significant for all tests.

\section{Results}

Table 1 presents the means, standard deviations, and the results of a two-way analysis of variance (ANOVA) with unpaired measurements for age, physical characteristics (height, weight, and body fat percentage), left ventricular ejection fraction rates (EF) and activity of daily living (ADL) scores according to gender. Significant interaction was found in age and height. The age was significantly higher values in females than in males in the young elderly group and in the old elderly group than in the young elderly group in both genders. The height was significantly higher values in males than in females in both age groups and in the young elderly than in the old elderly group in females. A significant gender difference was found in weight, body fat percentage, EF and ADL scores. The weight and ADL scores were significantly higher in males, and EF and body fat percentages were significantly higher in females. A significant age-related difference was found in body fat percentage and ADL scores. Body fat percentage was significantly higher in the old elderly group, and ADL scores were significantly higher in the young elderly group. Table 2 shows the means and standard deviations of each variable according to gender and age (young elderly group and old elderly group) and the results of two-way ANOVA with repeated measures and a multiple-comparison test. Significant differences based on gender were found in all tests except for TUG test and one-legged balance with eyes open (old elderly group); grip strength ( $\mathrm{F}=$ 203.36, $\mathrm{p}<0.05)$, sit-ups $(\mathrm{F}=9.30, \mathrm{p}<0.05)$, and 6-min walking tests $(\mathrm{F}=9.98, \mathrm{p}<0.05)$ showed a higher value in males and $10-\mathrm{m}$ obstacle walking time test $(\mathrm{F}=13.26, \mathrm{p}<0.05)$ showed a lower value in males; the sitting trunk flexion test $(\mathrm{F}=20.30, \mathrm{p}<0.05)$ and stepping by sitting position $(\mathrm{F}=6.54, \mathrm{p}<0.05)$ tests showed higher values in females. Significant age-related differences were found in all tests except sit-ups; the young elderly group showed higher values in grip strength $(F=25.38, p<0.05)$, 6-min walking $(F=28.09, p<0.05)$, sitting trunk flexion ( $F=7.98, p<0.05)$, and stepping by sitting position tests $(F=7.34, p<0.05)$ than the old elderly group and lower values in TUG $(\mathrm{F}=30.54, \mathrm{p}<0.05)$ and 10 -m obstacle walking time tests $(\mathrm{F}=33.24$, $\mathrm{p}$ $<0.05)$. Significant interaction was found in one-legged balance with eyes open test $(F=4.19$, $p<0.05)$. This value was higher in males than in females in the young elderly group and in the young elderly group than in the old elderly group in males.

\section{Discussion}

Physical function measurements of the elderly during the maintenance period are often excluded because of the physical burden, and hence, reports related to the physical functions of the elderly population are very limited [16]. This study clarified the gender and age-related differences of physical functions in the elderly who participated in exercise therapy for 1 year.

Muscle strength is generally superior in males compared with that in females [21] [22]. The failure of various physical functions with age cannot be avoided; however, it is important to maintain physical functions by exercise and physical activity [2]. In the present results, males also exhibited superior muscle strength to females, and the young elderly group showed superior muscle strength to the old elderly group in both genders. Ishizaki et al. [23] and Lynch et al. [24] reported that the decrease in grip strength was significant in males. It can be inferred that grip strength of the old elderly group in this study was inferior to that of the young elderly group of both genders. 
Table 1. Means, standard deviation of physical characteristics of participants by gender and age-level, results of two-way ANOVA and multiple comparison.

\begin{tabular}{|c|c|c|c|c|c|c|c|c|c|c|c|}
\hline & \multicolumn{2}{|c|}{ Young elderly } & \multicolumn{2}{|c|}{ Old elderly } & \multirow{2}{*}{ Factor } & \multicolumn{4}{|c|}{ Two-way ANOVA } & \multicolumn{2}{|c|}{ Multiple comparison } \\
\hline & Mean & SD & Mean & SD & & df & F value & $\mathrm{p}$ value & $\eta 2$ & Sex & Age -level \\
\hline Age (years) & & & & & Sex & 1 & 0.20 & 0.66 & 0.00 & $\begin{array}{c}\text { Young: } \\
\text { Male < Female }\end{array}$ & $\begin{array}{c}\text { Male: } \\
\text { Young < Old }\end{array}$ \\
\hline Male & 70.4 & 3.3 & 80.2 & 3.8 & Age-level & 1 & $285.96^{*}$ & 0.01 & 0.64 & Old: ns & $\begin{array}{c}\text { Female: } \\
\text { Young < Old }\end{array}$ \\
\hline \multirow[t]{2}{*}{ Female } & 71.9 & 2.2 & 79.1 & 3.2 & Interaction & 1 & $6.81^{*}$ & 0.01 & 0.04 & & \\
\hline & & & & & Error & 163 & & & & & \\
\hline \multicolumn{3}{|c|}{ Height (cm) } & & & Sex & 1 & $128.00^{*}$ & 0.01 & 0.44 & $\begin{array}{c}\text { Young: } \\
\text { Male > Female }\end{array}$ & Male: ns \\
\hline Male & 162.4 & 6.6 & 161.3 & 5.0 & Age-level & 1 & $12.33^{*}$ & 0.01 & 0.07 & $\begin{array}{c}\text { Old: } \\
\text { Male > Female }\end{array}$ & $\begin{array}{c}\text { Female: } \\
\text { Young > Old }\end{array}$ \\
\hline \multirow[t]{2}{*}{ Female } & 155.0 & 5.4 & 150.4 & 3.7 & Interaction & 1 & $4.57^{*}$ & 0.03 & 0.03 & & \\
\hline & & & & & Error & 163 & & & & & \\
\hline \multicolumn{2}{|c|}{ Weight (kg) } & & & & Sex & 1 & $23.17^{*}$ & 0.01 & 0.12 & & \\
\hline Male & 56.3 & 6.9 & 59.6 & 7.5 & Age-level & 1 & 2.40 & 0.12 & 0.02 & & \\
\hline \multirow[t]{2}{*}{ Female } & 52.4 & 5.5 & 52.6 & 8.4 & Interaction & 1 & 1.89 & 0.17 & 0.01 & & \\
\hline & & & & & Error & 163 & & & & & \\
\hline \multicolumn{3}{|c|}{ Percent body fat (\%) } & & & Sex & 1 & $94.41^{*}$ & 0.01 & 0.39 & & \\
\hline Male & 21.2 & 4.7 & 23.7 & 6.1 & Age-level & 1 & $11.73^{*}$ & 0.01 & 0.07 & & \\
\hline \multirow[t]{2}{*}{ Female } & 30.2 & 6.0 & 34.7 & 7.5 & Interaction & 1 & 0.99 & 0.32 & 0.00 & & \\
\hline & & & & & Error & 151 & & & & & \\
\hline \multicolumn{3}{|c|}{ Ejection fraction rate (\%) } & & & Sex & 1 & $38.90^{*}$ & 0.01 & 0.23 & & \\
\hline Male & 61.1 & 16.1 & 63.0 & 14.7 & Age-level & 1 & 0.92 & 0.34 & 0.00 & & \\
\hline \multirow[t]{2}{*}{ Female } & 73.3 & 7.7 & 75.2 & 5.6 & Interaction & 1 & 0.00 & 1.00 & 0.00 & & \\
\hline & & & & & Error & 132 & & & & & \\
\hline \multicolumn{2}{|c|}{ ADL score (point) } & & & & Sex & 1 & $19.65^{*}$ & 0.01 & 0.11 & & \\
\hline Male & 32.0 & 3.4 & 29.4 & 5.1 & Age-level & 1 & $16.46^{*}$ & 0.01 & 0.09 & & \\
\hline \multirow[t]{2}{*}{ Female } & 29.2 & 4.3 & 25.9 & 4.5 & Interaction & 1 & 0.21 & 0.65 & 0.00 & & \\
\hline & & & & & Error & 163 & & & & & \\
\hline
\end{tabular}

M: Mean, SD: standard deviation, df: degree of freedom, $\eta 2$ : effect size, ${ }^{*}: \mathrm{p}<0.05$. Male $>$ Female: Male shows significantly larger results than female. Male < Female: Female shows significantly larger results than male. Young > Old: The young elderly group shows significantly larger results than the old elderly group. Young < Old: The old elderly group shows significantly larger results than the young elderly group. Ns: not significant.

Sit-ups as an index of muscle endurance are generally not measured in the elderly, considering the safety concerns related to the high difficulty of the test [25]. Muscle endurance and muscle strength decrease with age and are superior in males compared with those in females [26] [27]. In the present study, the rate of sit-ups was superior in males compared with that in females, but significant age-related differences were not found. Maruyama et al. [28] reported that the decrease in muscle endurance with age is greater in healthy elderly males. This problem should be examined by longitudinal data in the future. 
Table 2. Means, standard deviations of physical function tests by gender and age-level, results of two-way ANOVA and multiple comparisons.

\begin{tabular}{|c|c|c|c|c|c|c|c|c|c|c|c|}
\hline & \multicolumn{2}{|c|}{ Young elderly } & \multicolumn{2}{|c|}{ Old elderly } & \multirow{2}{*}{ Factor } & \multicolumn{4}{|c|}{ Two-way ANOVA } & \multicolumn{2}{|c|}{ Multiple comparison } \\
\hline & Mean & SD & Mean & SD & & df & F value & Pvalue & $\eta 2$ & Sex & Age-level \\
\hline \multicolumn{5}{|c|}{ Grip strength (kg) } & Sex & 1 & $203.36^{*}$ & 0.01 & 0.56 & & \\
\hline Male & 33.3 & 5.5 & 29.1 & 3.7 & Age-level & 1 & $25.38^{*}$ & 0.01 & 0.14 & & \\
\hline \multirow[t]{2}{*}{ Female } & 22.9 & 4.5 & 20.3 & 3.5 & Interaction & 1 & 1.47 & 0.23 & 0.01 & & \\
\hline & & & & & Error & 163 & & & & & \\
\hline \multicolumn{5}{|c|}{ Ten-meter obstacle walking time (sec) } & Sex & 1 & $13.26^{*}$ & 0.01 & 0.08 & & \\
\hline Male & 5.9 & 1.2 & 7.4 & 2.0 & Age-level & 1 & $33.24^{*}$ & 0.01 & 0.17 & & \\
\hline \multirow[t]{2}{*}{ Female } & 6.9 & 1.2 & 8.3 & 1.7 & interaction & 1 & 0.06 & 0.82 & 0.00 & & \\
\hline & & & & & Error & 163 & & & & & \\
\hline \multicolumn{5}{|c|}{ One-legged balance with eyes open(sec) } & Sex & 1 & 2.28 & 0.13 & 0.03 & $\begin{array}{c}\text { Young: } \\
\text { Male > Female }\end{array}$ & $\begin{array}{c}\text { Male: } \\
\text { Young > Old }\end{array}$ \\
\hline Male & 85.7 & 41.5 & 41.6 & 42.9 & Age-level & 1 & $18.27^{*}$ & 0.01 & 0.01 & Old: ns & Female: ns \\
\hline \multirow[t]{2}{*}{ Female } & 60.9 & 47.7 & 45.4 & 43.6 & Interaction & 1 & $4.19^{*}$ & 0.04 & 0.03 & & \\
\hline & & & & & Error & 163 & & & & & \\
\hline \multicolumn{2}{|c|}{ Sit-ups (point) } & & & & Sex & 1 & $9.30^{*}$ & 0.01 & 0.05 & & \\
\hline Male & 7.5 & 5.8 & 6.4 & 5.0 & Age-level & 1 & 0.11 & 0.75 & 0.00 & & \\
\hline \multirow[t]{2}{*}{ Female } & 4.2 & 5.1 & 4.8 & 4.8 & Interaction & 1 & 1.11 & 0.29 & 0.00 & & \\
\hline & & & & & Error & 161 & & & & & \\
\hline \multicolumn{5}{|c|}{ Sitting trunk flexion (cm) } & Sex & 1 & $20.30^{*}$ & 0.01 & 0.11 & & \\
\hline Male & 28.4 & 8.4 & 25.7 & 10.2 & Age-level & 1 & $7.98^{*}$ & 0.01 & 0.05 & & \\
\hline \multirow[t]{2}{*}{ Female } & 35.8 & 8.3 & 30.8 & 7.5 & Interaction & 1 & 0.66 & 0.42 & 0.00 & & \\
\hline & & & & & Error & 163 & & & & & \\
\hline \multicolumn{5}{|c|}{ Six minutes walking (m) } & Sex & 1 & $9.98^{*}$ & 0.01 & 0.06 & & \\
\hline Male & 595.1 & 77.3 & 539.5 & 60.3 & Age-level & 1 & $28.09^{*}$ & 0.01 & 0.16 & & \\
\hline \multirow[t]{2}{*}{ Female } & 562.8 & 58.0 & 502.9 & 73.4 & Interaction & 1 & 0.04 & 0.85 & 0.00 & & \\
\hline & & & & & Error & 149 & & & & & \\
\hline \multicolumn{4}{|c|}{ Timed up \& go (sec) } & & Sex & 1 & 1.70 & 0.19 & 0.01 & & \\
\hline Male & 5.5 & 0.8 & 6.5 & 1.2 & Age-level & 1 & $30.54^{*}$ & 0.01 & 0.16 & & \\
\hline \multirow[t]{2}{*}{ Female } & 5.8 & 0.9 & 6.5 & 0.9 & Interaction & 1 & 1.02 & 0.32 & 0.00 & & \\
\hline & & & & & Error & 163 & & & & & \\
\hline \multicolumn{5}{|c|}{ Stepping by sitting position (point) } & Sex & 1 & $6.54^{*}$ & 0.01 & 0.04 & & \\
\hline Male & 33.3 & 7.5 & 30.2 & 5.4 & Age-level & 1 & $7.34^{*}$ & 0.01 & 0.04 & & \\
\hline \multirow[t]{2}{*}{ Female } & 34.6 & 4.4 & 33.2 & 4.4 & Interaction & 1 & 0.97 & 0.33 & 0.00 & & \\
\hline & & & & & Error & 149 & & & & & \\
\hline
\end{tabular}

M: Mean, SD: standard deviation, df: degree of freedom, $\eta 2$ : effect size, ${ }^{*}: p<0.05$. Male $>$ Female: Male shows significantly larger results than female. Young > Old: The young elderly group shows significantly larger results than the old elderly group. Ns: not significant. 
Whole-body endurance and walking ability were superior in males compared with those in females and in the young elderly group compared with those in the old elderly group in both genders. Weiss et al. [29] examined the gender difference and age-related changes in maximum oxygen consumption (VO2max) for healthy elderly aged 62 - 92 years. The study found that VO2max was superior in males and a decrease with age was larger in males, but no difference was found based on gender in those $>80$ years of age. Maruyama et al. [28] reported that walking ability decreases in $>75$-year-old elderly males and 60-year-old elderly females; in brief, the decreased onset age is earlier in females. From the present results, it can be inferred that endurance and walking ability are superior in males compared with females and decrease with age in both genders.

Stepping by sitting position was superior in females compared with that in males at all age levels, and the young elderly group was superior in both genders. Minami et al. [18] reported that there was no difference in agility of the total body and fingers in healthy elderly people of both genders. Kent et al. [30] reported that tapping speed showed an age-related difference but not a gender-related difference. In this study, only an age-related difference was consistent with the results of previous studies, e.g., Kent et al. [30]. Leg agility can be improved by a moderate exercise stimulus [31]. One possible reason for female superiority in this area is that the intensity of the regular exercise therapy in this study is more suitable for females. In addition, it may be affected by the amount of exercise and homework besides exercise therapy by group sports. It is necessary to examine and include these factors in the future.

There was no gender-related difference in the ability to move, and the young elderly group was superior in this function. The TUG test reflects the walking ability, muscle strength of the lower limbs, balance ability (equilibrium), and ADL [20] [32] [33] and is used for an index of falling prediction [34]. It is considered that because the present participants were considerably faster than $13.5 \mathrm{~s}$ of the cut-off value, fall risk was less. Shimada et al. [35] reported that based on the results of the TUG test for healthy elderly people (mean age, 74.8 years), males were superior to females at all age levels and an attenuation of TUG performance ability by aging was observed in both genders. In short, the present results differed on the effect of gender. The TUG test was measured as the time required to walk starting and rising from a sitting position on a chair and returning to the original seated position. This activity demands agility and quickness of the total body [20]. No gender-related differences could be found in the TUG test, because agility and quickness of the total body were superior in females compared with those in males affected in this study.

The ability to balance generally decreases with age, and males are superior to females [18] [36]. Balance ability relates closely to leg strength and walking ability because it was evaluated in a standing posture [37]-[39]. Sugimoto et al. [40] reported that the one-legged balance with eyes open was not improved in the pre-frail elderly group in females following 1-year regular exercise program for prevention once a week. One-legged balance with eyes open test was possible for more than $30 \mathrm{~s}$ in all age groups in both genders in this study. Murata et al. reported that the elderly can prevent falling if they can perform this test for $30 \mathrm{~s}$ [25]. Therefore, fall risk is low in both genders. A significant age-related difference was not found in females, but the performance of males was inferior in the old elderly group and superior compared with females in the young elderly group. Bohannon et al. [41] reported that balance ability decreased after 60 years of age and decreased markedly in the elderly group older than 70 years of age. They clarified that balance ability decreased in males in the old elderly group, but was maintained in females in this study. For this reason, we considered that the intensity of exercise used in this study was low in males. This point requires further investigation.

Sitting trunk flexion is generally superior in females compared with that in males [42] [43]. It is reported that the range of joint motion, as an index of flexibility, decreased with age, and the ranges of body trunk convolution, hip joint, and ankle joint motions decreased remarkably [44]. On the other hand, the decrease with age is minor for flexibility compared with balance ability, agility, and endurance [28] [45]. The present results showed that flexibility was superior in females compared with that in males in both the young and the old elderly groups. Age-related differences in flexibility differed from reports of Pereira and Baptista [45] and Maruyama et al. [28]. The present exercise program, including table tennis, soft tennis, and ergometry, might not suppress the flexibility decreases caused by aging.

Participants in the present study included 167 elderly individuals during maintenance period who participated in regular exercise program in the region for one year. Because of the difficulty of having the same participants for one year and it is nearly impossible to set a control group in the exercise-guidance field. However, it is necessary to set a control group as many healthy elderly as possible and adequately examine the effect of the above program from now. 


\section{Conclusion}

Characteristics of physical functions in the elderly during the maintenance period differ in both genders; males are superior in muscle strength, muscle endurance, whole-body endurance, and walking ability, and females are superior in flexibility and agility. The old elderly people are inferior to young elderly people in many physical functions.

\section{References}

[1] Care Prevention Manual Revision Committee. Preventive Care Manual (Revised Version). http://www.mhlw.go.jp/topics/2009/05/tp0501-1.html

[2] Demura, S. (2008) Health and Sports Science Lecture. Kyorin Publishers Ltd., Tokyo.

[3] Fried, L.P., Tangen, C.M., Walston, J., Newman, A.B., Hirsch, C., Gottdiener, J., Seeman, T., Tracy, R., Kop, W.J, Burke, G. and McBurnie, M.A. Cardiovascular Health Study Collaborative Research Group (2001) Frailty in Older Adults: Evidence for a Phenotype. The Journals of Gerontology: Series A, 56, M1461-M1456. http://dx.doi.org/10.1093/gerona/56.3.M146

[4] Guralnik, J.M., Simonsick, E.M., Ferrucci, L., Glynn, RJ, Berkman, L.F., Blazer, D.G., Scherr, P.A. and Wallace, R.B. (1994) A Short Physical Performance Battery Assessing Lower Extremity Function: Association with Self-Reported Disability and Prediction of Mortality and Nursing Home Admission. Journal of Gerontology, 49, M85-M94. http://dx.doi.org/10.1093/geronj/49.2.M85

[5] Atlantis, E., Martin, S.A., Haren, M.T., Taylor, A.W. and Wittert, G.A. (2009) Inverse Associations between Muscle Mass, Strength, and the Metabolic Syndrome. Metabolism, 58, 1013-1022. http://dx.doi.org/10.1016/j.metabol.2009.02.027

[6] Carnethon, M.R., Gulati, M. and Greenland, P. (2005) Prevalence and Cardiovascular Disease Correlates of Low Cardiorespiratory Fitness in Adolescents and Adults. Journal of the American Medical Association, 294, 2981-2988. http://dx.doi.org/10.1001/jama.294.23.2981

[7] Sawada, S.S., Lee, I.M., Naito, H., Tsukamoto, K., Muto, T. and Blair, S.N. (2010) Muscular and Performance Fitness and the Incidence of Type 2 Diabetes: Prospective Study of Japanese Men. Journal of Physical Activity \& Health, 7, 627-632.

[8] Katzmarzyk, P.T., Craig, C.L. and Gauvin, L. (2007) Adiposity, Physical Fitness and Incident Diabetes: The Physical Activity Longitudinal Study. Diabetologia, 50, 538-544. http://dx.doi.org/10.1007/s00125-006-0554-3

[9] Katzmarzyk, P.T. and Craig, C.L. (2002) Musculoskeletal Fitness and Risk of Mortality. Medicine\& Science in Sports \& Exercise, 34, 740-744. http://dx.doi.org/10.1097/00005768-200205000-00002

[10] Menz, H.B., Morris, M.E. and Lord, S.R. (2006) Foot and Ankle Risk Factors for Falls in Older People. A Prospective Study. Journals of Gerontology Series A: Biological Sciences and Medical Sciences, 61, 866-870. http://dx.doi.org/10.1093/gerona/61.8.866

[11] Suzuki, T., Yoshida, H., Kim, H., Yukawa, H., Sugiura, M., Furuna, T., Nishizawa, S., Kumagai, S., Shinkai, S., Ishizaki, T., Watanabe, S. and Shibata, H. (2003) Walking Speed as a Good Predictor for Maintenance of I-ADL among the Rural Community Elderly in Japan: A 5-Year Follow-Up Study from TMIG-LISA. Geriatrics \& Gerontology International, 3, S6-S14. http://dx.doi.org/10.1111/j.1444-0594.2003.00090.x

[12] Ministry of Education Science Sports and Culture (2000) Newphysical Fitness Test-for Meaningful Use. Gyosei Publishers Ltd., Tokyo.

[13] Joint Study Group Report of Japanese Circulation Society (2012) Guidelines for Rehabilitation in Cardiovascular Disease (Revised Edition 2012).http://square.umin.ac.jp/jacr/link/doc/JCS2012_nohara_d.pdf

[14] Ueshima, K., Kamata, J., Kobayashi, N., Saito, M., Sato, S., Kawazoe, K. and Hiramori, K. (2004) Effects of Exercise Training after Open Heart Surgery on Quality of Life and Exercise Tolerance in Patients with Mitral Regurgitation or Aortic Regurgitation. Japanese Heart Journal, 45, 789-797. http://dx.doi.org/10.1536/jhj.45.789

[15] Hambrecht, R., Wolf, A., Gielen, S., Linke, A., Hofer, J., Erbs, S., Schoene, N. and Schuler, G. (2000) Effect of Exercise on Coronary Endothelial Function in Patients with Coronary Artery Disease. NewEngland Journal of Medicine, 342, 454-460. http://dx.doi.org/10.1056/NEJM200002173420702

[16] Kurose, S., Imai, M., Kagitani, K., Shithino,Y., Yamashita, M., Uenishi, K., Hamamithi, S., Masuda, I. and Hashimoto, T. (2009) Comparison Physical Fitness in Patients with or without Cardiac Disease during a Maintenance Phase of Cardiac Rehabilitation. Japanese Association of Cardiac Rehabilitation, 14, 263-268.

[17] Hamazaki, H. and Shimomura, M. (2005) Examination about Amount of Activities and Intensity in Sports Cardiac Rehabilitation. Japanese Society for Adapted Physical Education and Exercise, 3, 48-56. 
[18] Minami, M., Demura, S., Satou, S., Kasuga, K., Matsuzawa, K. and Goshi, F. (1998) The Changing of Physique and Physical Fitness with Age. Japanese Journal of Physical Fitness and Sports Medicine, 47, 601-615.

[19] Japan Industrial Safety and Health Association (2009) Fall Such as Disaster Risk Assessment Self-Check Implementation Manual. Ministry of Education Science Sports and Culture Press, Tokyo. http://www.mhlw.go.jp/new-info/kobetu/roudou/gyousei/anzen/dl/101006-1a 07.pdf.

[20] Podsiadlo, D. and Richardson, S. (1991) The Timed “up \& Go” A Test of Basic Functional Mobility for Frail Elderly Persons. Journal of the American Geriatrics Society, 39, 142-148.

[21] Tokyo Metropolitan University Physical Fitness Standard Study Group (2007) Physical Fitness Standard Value of New Japanese (2). Fumidou Publishers Ltd., Tokyo.

[22] Valour, D., Ochala, J., Ballay, Y. and Pousson M. (2003) The Influence of Aging on the Force-Velocity-Power Characteristics of Human Elbow Flexor Muscles. Experimental Gerontology, 38, 387-395. http://dx.doi.org/10.1016/S0531-5565(02)00265-6

[23] Ishizaki, T., Furuna, T., Yoshida, Y., Iwasa, H., Shimada, H., Yoshida, H., Kumagai, S. and Suzuki, T. (2011) Declines in Physical Performance by Sex and Age among Nondisabled Community-Dwelling Older Japanese during a 6-Year Period. Journal of Epidemiology, 21, 176-183. http://dx.doi.org/10.2188/jea.JE20100138

[24] Lynch, N.A., Metter, E.J., Lindle, R.S., Fozard, J.L., Tobin, J.D., Roy, T.A., Fleg, J.L. and Hurley, B.F. (1999) Muscle quality. I. Age-Associated Differences between Arm and Leg Muscle Groups. Journal of Applied Physiology, 86, 188-194.

[25] Murata, S., Otao, H., Murata, J., Horie, J., Miyazaki, J., Yamazaki, S. and Mizota, K. (2010) Relationships between Ability to Raise the Upper Body and Physical and Psychological Functions of Community-Dwelling Elderly. Journal of Physical Therapy Science, 25, 115-119.

[26] Ota, M., Ikezoe, T., Kaneoka, K. and Ichihashi, N. (2012) Age-Related Changes in the Thickness of the Deep and Superficial Abdominal Muscles in Women. Archives of Gerontology and Geriatrics, 55, 26-30. http://dx.doi.org/10.1016/j.archger.2012.03.007

[27] Kanehisa, H., Miyatani, M., Azuma, K., Kuno, S. and Fukunaga, T. (2004) Influences of Age and Sex on Abdominal Muscle and Subcutaneous Fat Thickness. European Journal of Applied Physiology, 91, 534-537. http://dx.doi.org/10.1007/s00421-003-1034-9

[28] Maruyama, Y., Furukawa, M. and Takei, M. (2004) Aging and Physical Strength Change in the Senior Citizens’ Club Officers of Participation Leader Training Session. Journal of Health and Sports Science Juntendo, 8, 43-47.

[29] Weiss, E.P., Spina, R.J., Holloszy, J.O. and Ehsani, A.A. (2006) Gender Differences in the Decline in Aerobic Capacity and Its Physiological Determinants during the Later Decades of Life. Journal of Applied Physiology, 101, 938-944. http://dx.doi.org/10.1152/japplphysiol.01398.2005

[30] Kent-Braun, J.A. and Ng, A.V. (1999) Specific Strength and Voluntary Muscle Activation in Young and Elderly Women and Men. Journal of Applied Physiology, 87, 22-29.

[31] Batista, L.H., Vilar, A.C., de Almeida Ferreira, J.J., Rebelatto, J.R. and Salvini, T.F. (2009) Active Stretching Improves Flexibility, Joint Torque, and Functional Mobility in Older Women. American Journal of Physical Medicine \& Rehabilitation, 88, 815-822. http://dx.doi.org/10.1097/PHM.0b013e3181b72149

[32] Samson, M.M., Meeuwsen, I.B., Crowe, A., Dessens, J.A., Duursma, S.A. and Verhaar, H.J. (2000) Relationship between Physical Performance Measures, Age, Height and Body Weight in Healthy Adults. Age and Ageing, 29, $235-242$. http://dx.doi.org/10.1093/ageing/29.3.235

[33] Bischoff, H.A., Conzelmann, M., Lindemann, D., Singer-Lindpaintner, L., Stucki, G., Vonthein, R., Dick, W., Theiler, R. and Stähelin, H.B. (2001) Self-Reported Exercise before Age 40: Influence on Quantitative Skeletal Ultrasound and Fall Risk in the Elderly. Archives of Physical Medicine and Rehabilitation, 82, 801-806. http://www.sciencedirect.com/science/article/pii/S0003999301748691

[34] Shumway-Cook, A., Brauer, S. and Woollacott, M. (2000) Predicting the Probability for Falls in Community-Dwelling Older Adults Using the Timed Up \& Go Test. Physical Therapy, 80, 896-903.

[35] Shimada, H., Furyna, T., Obuvhi, S. and Sugiura, M. (2006) Timed Up \& Go Test Is a Useful Assessment Tool for Community Health in Elderly People. Japanese Physical Therapy Science, 33, 105-111.

[36] Cooper, R., Hardy, R., Aihie Sayer, A., Ben-Shlomo, Y., Birnie, K., Cooper, C., Craig, L., Deary, I.J., Demakakos, P., Gallacher, J., McNeill, G., Martin, R.M., Starr, J.M., Steptoe, A. and Kuh, D. (2011) Age and Gender Differences in Physical Capability Levels from Mid-Life Onwards: The Harmonisation and Meta-Analysis of Data from Eight UK Cohort Studies. PLoS ONE, 6, Article ID: e27899. http://dx.doi.org/10.1371/journal.pone.0027899

[37] Herman, S., Kiely, D.K., Leveille, S., O’Neil, E., Cyberey, S. and Bean, J.F. (2005) Upper and Lower Limb Muscle Power Relationships in Mobility-Limited Older Adults. Journals of Gerontology Series A-Biological Sciences \& Medical 
Sciences, 60, 476-480. http://dx.doi.org/10.1093/gerona/60.4.476

[38] Hess, J.A. and Woollacott, M. (2005) Effect of High-Intensity Strength-Training on Functional Measures of Balance Ability in Balance Impaired Older Adults. Journal of Manipulative and Physiological Therapeutics, 28, 582-590. http://dx.doi.org/10.1016/i.jmpt.2005.08.013

[39] Ikai, T., Tatsuno, H. and Uno, S. (2006) Relationship between Walking Ability and Balance Function. Japanese Association of Rehabilitation Medicine, 43, 823-833.

[40] Sugimoto, H., Demur, a S., Nagasawa, Y. and Shimomura, S. (2013) Changes in the Physical Functions of Pre-Frail Elderly Women Following Participation in a One-Year Preventative Exercise Program. Geriatrics \& Gerontology International, in press.

[41] Bohannon, R.W., Larkin, P.A., Cook, A.C., Gear, J. and Singer, J. (1984) Decrease in Timed Balance Test Scores with Aging. Physical Therapy, 64, 1067-1070.

[42] Gusi, N., Prieto, J., Olivares, P.R., Delgado, S., Quesada, F. and Cebrián, C. (2012) Normative Fitness Performance Scores of Community-Dwelling Older Adults in Spain. Journal of Aging and Physical Activity, 20, 106-126.

[43] Riemann, B.L., DeMont, R.G., Ryu, K. and Lephart, S.M. (2001) The Effects of Sex, Joint Angle, and the Gastrocnemius Muscle on Passive Ankle Joint Complex Stiffness. Journal of Athletic Training, 36, 369-375.

[44] Hoeger, W.K. and Hoeger, S.A. (2000) A Life Physical Fitness and Wellness. 6th Edition, Chicago Morton Publishers Ltd., Chicago.

[45] Pereira, C. and Baptista, F. (2012) Variation of the Different Attributes that Support the Physical Function in CommunityDwelling Older Adults. Journal of Sports Medicine and Physical Fitness, 52, 190-197. 